\title{
Orbital floor fracture
}

\author{
Christian El-Hadad MDCM, Jean Deschênes MD, Bryan Arthurs MD
}

Cite as: CMAJ 2021 February 22;193:E289. doi: 10.1503/cmaj.200657

\section{Suspect orbital floor fracture if the orbit has been affected by \\ 1 blunt trauma}

After blunt trauma from a ball or fist, a fall or motor vehicle collision, the floor of the orbit can fracture without involving the orbital rim or other facial bones. This may occur because of a marked pressure rise within the orbit when the globe is suddenly displaced posteriorly (hydraulic theory) or direct transmission of forces to the orbital floor in an anterior-posterior direction following an impact to the orbital rim (buckling phenomenon). ${ }^{1}$

\section{Patients present with changes in visual acuity and pain on extraocular movement}

Patients usually report acute visual changes such as monocular blurred vision or binocular diplopia, and pain on extraocular movements. ${ }^{2}$ Examination of the gross anatomic integrity of the eyeball, visual acuity using an electronic application or a paper eye chart and extraocular movement in all directions of gaze should be conducted.

\section{3}

\section{Noncontrast computed tomography (CT) is the diagnostic gold} standard

Orbital radiographs (Caldwell and Waters views) accurately diagnose $68 \%-78 \%$ of fractures compared with CT and remain a useful screening modality for orbital foreign bodies. ${ }^{3}$ Noncontrast CT is the gold standard, however, and allows evaluation of the position of extraocular muscles, presence of retrobulbar hemorrhage and whether the orbital fat has herniated, which will direct management. ${ }^{3}$

\section{Not all fractures require urgent ophthalmic assessment}

Patients should be referred for urgent ophthalmology assessment when globe rupture is suspected, binocular diplopia is present when the upper eyelid is raised manually by the clinician (particularly in up gaze) in the presence of periocular edema, visual acuity is less than or equal to 20/40, or muscle entrapment on CT imaging is suspected. ${ }^{4}$ Otherwise, an outpatient referral to ophthalmology within 1 to 2 weeks is appropriate. ${ }^{5}$ Patients with isolated orbital floor fractures are safe to travel by land.

\section{Most fractures heal spontaneously without complication}

Patients should avoid forceful blowing of the nose for 4-6 weeks to avoid pneumo-orbit. ${ }^{2}$ A 7 -day course of prednisone $(1 \mathrm{mg} / \mathrm{kg}$ for $7 \mathrm{~d}$, tapered over 4 d) administered orally with gram-positive antibiotic coverage, such as cephalexin or clindamycin, can be considered in cases of orbital edema that prevents eye opening. ${ }^{6}$

\section{References}

1. Ahmad F, Kirkpatrick NA, Lyne J, et al. Buckling and hydraulic mechanisms in orbital blowout fractures: Fact or fiction? J Craniofac Surg 2006;17:438-41.

2. Homer N, Huggins A, Durairaj VD. Contemporary management of orbital blowout fractures. Curr Opin Otolaryngol Head Neck Surg 2019;27:310-6.

3. Kubal WS. Imaging of orbital trauma. Radiographics 2008; 28:1729-39.

4. Mellema PA, Dewan MA, Lee MS, et al. Incidence of ocular injury in visually asymptomatic orbital fractures. Ophthal Plast Reconstr Surg 2009;25:306-8.

5. Richani K, Do TH, Merritt HA, et al. Screening criteria for detecting severe ocular injuries in the setting of orbital fractures. Ophthal Plast Reconstr Surg 2019;35:609-14.

6. Courtney DJ, Thomas S, Whitfield PH. Isolated orbital blowout fractures: survey and review. Br J Oral Maxillofac Surg 2000;38:496-504

\section{Competing interests: None declared.}

This article has been peer reviewed.

Affiliation: Ophthalmology \& Visual Sciences, Faculty of Medicine and Health Sciences, McGill University, Montréal, Que.

Content licence: This is an Open Access article dis tributed in accordance with the terms of the Creative Commons Attribution (CC BY-NC-ND 4.0) licence, which permits use, distribution and reproduction in any medium, provided that the original publication is properly cited, the use is noncommercial (i.e., research or educational use), and no modifications or adaptations are made. See: https://creativecommons. org/licenses/by-nc-nd/4.0/

Correspondence to: Christian El-Hadad, Christian.haddad@mcgill.ca

CMAJ invites submissions to "Five things to know about ..." Submit manuscripts online at http://mc. manuscriptcentral.com/cmaj 